\title{
Perencanaan Program Teknik Stimulasi Pengasaman Menggunakan Metode Matrix Acidizing Pada Sumur FIA \\ PT Pertamina EP Asset 3 Cirebon
}

Rahma Musyafia Muhammad

Politeknik Energi dan Mineral Akamigas, Cepu

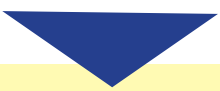

ABSTRAK

Stimulasi pengasaman dapat didefenisikan sebagai pekerjaan yang dilakukan terhadap sumur dengan tujuan meningkatkan laju produksi dengan jalan memperbaiki dan atau meningkatkan harga permeabilitas batuan dengan cara menginjeksikan asam ke dalam pori-pori formasi (antar butir, rongga-rongga, atau rekahan) atau melarutkan partikelpartikel penyumbat pori-pori. Maksud dari skripsi ini adalah memilih dan merencanakan jenis Stimulasi Acidizing yang sesuai dengan kondisi sumur produksi yang dalam hal ini batuan reservoir berjenis karbonat limestone, sehingga dengan dilakukannya stimulasi acidizing dengan menggunakan fluida stimulasi berbahan dasar Asam Hydrochloric (HCL), maka diharapkan kerusakan formasi (formation damage) akan tertanggulangi dan turunnya harga permeabilitas akibat damage akan kembali ke harga permeabilitas asli dari reservoir tersebut sehingga laju alir produksi akan meningkat.Metode yang digunakan dalam skripsi ini adalah dengan cara menganalisa kerusakan formasi dengan melihat sejarah produksi sumur, hasil analisa Pressure Build Up Test, dan juga dengan melihat kurva IPR sumur. Kemudian mendesain stimulasi acidizing melalui metode perhitungan trial \& error dengan beberapa pengasaman yang sudah ditentukan.

Kata kunci: Program Matrix Acidizing, Permasalahan Sumur, Peramalan Sumur, Kajian Keekonomian

\section{PENDAHULUAN}

Dalam industri perminyakan nilai produksi dari suatu sumur sangat berpengaruh besar. Apabila nilai produksi dari sumur tersebut menurun maka perusahaan akan menerima dampak kerugian. Masalah yang membuat nilai produksi sumur turun bias diakibatkan oleh kerusakan dari dalam sumur tersebut atau dari alat-alat yang ada di permukaan. Apabila nilai produksi menurun, maka pada sumur tersebut dapat dilakukan perbaikan sumur atau biasa disebut dengan well intervention. Salah satu metode well intervention adalah dilakukannya Acidizing. Metode ini dilakukan dengan cara penginjeksian asam dan bahan kimia yang digunakan untuk memperbaiki permasalahan yang terjadi di dalma sumur. Metode ini terbagi menjadi tiga yaitu Acid Washing, Matrix Acidizing, dan Acid Fracturing.

Dalam kesempatan ini penulis mengambil judul "PERENCANAAN PROGRAM TEKNIK STIMULASI MATRIX ACIDIZING PADA SUMUR FIA PT PERTAMINA EP ASSET 3“. Matrix acidizing dilakukan dengan cara menginjeksikan larutan asam dan bahan kimia tertentu 
secara langsung kedalam pori-pori batuan formasi disekita lubang sumur dengan tekanan penginjeksian dibawah tekanan rekah formasi. Hal tersebut dilakukan dengan tujuan agar reaksi menyebar ke formasi secara radial pada formasi target.

\section{METODE PENELITIAN}

Metodologi pengumpulan data dalam penelitian skripsi adalah sebagai berikut :

- Pengumpulan data primer dan sekunder mengenai well history, data produksi, data adam yang akan diinjeksikan, SOP matrix acidizing, dan data penunjang lainnya.

- Mengimplementasikan data primer dan data sekunder yang terkumpul, sehingga diperoleh scenario kajian ekonomi teknik program matrix acidizing yang dilakukan pada sumur produksi.

\section{HASIL PENELITIAN DAN PEMBAHASAN}

\section{A. Kondisi Lapangan}

Permasalahan produksi di lapangan Tambun adalah fluida dengan viskositas yang tinggi, kepasiran dan formation/wellbore damage yang disebabkan oleh scale dll. Fluida dengan jenis viskositas yang tinggi dapat ditangani dengan cara melakukan enhanced oil recovery yaitu steam flood yang bisa membuat viskositas fluida menjadi turun sehingga fluida dapat dipompakan ke permukaan. Untuk permasalahan kepasiran dapat ditangani dengan menggunakan gravel pack sehingga pasir akan terlambat untuk terproduksi ke permukaan bersama minyak. Sedangkan permasalahan scale di wellbore dapat ditangani dengan cara melakukan pengasaman jenis matrix acidizing yaitu untuk menanggulangi atau mengurangi kerusakan formasi guna peningkatan laju produksi dengan melarutkan sebagian batuan, dengan demikian akan memperbesar saluran yang tersedia atau bisa lebih dari itu dengan membuka saluran baru sebagai akibat adanya pelarut atau reaksi antara acid dengan batuan.

\section{B. Identifikasi Kandidat Sumur yang Akan di Stimulasi}

Formation/Wellbore damage dapat didefinisikan sebagai terjadinya penurunan produktivitas suatu sumur karena menurunnya harga permeabilitas batuan disekitar lubang sumur, yang mana dapat diakibatkan oleh tersumbatnya lubang bor, lubang perforasi maupun pori-pori dekat lubang bor. Penyebab utama formation/wellbore damage jenis scale adanya kontak antara formasi dengan fluida yang tidak sesuai sehingga mengakibatkan terbentuknya di sekitar formasi/lubang sumur yang biasa disebut scale dapat menghambat jalannya produksi. Beberapa parameter dibawah merupakan identifikasi suatu sumur yang termasuk dalam kandidat acid job menurut lapangan Tambun :

1. Formasinya homogen

2. Ukuran pori-porinya seragam

3. Kecepatan reaksi menurun secara uniform dengan berkurangnya konsentrasi asam

4. Beratnya limestone yang terlarut pada tiap pertambahan jarak menurun secara uniform sampai seluruh asam terpakai.

Kelarutan partikel-partikel/evektivitas pengasaman tergantung dari faktor-faktor yang mempengaruhi, diantaranya : 
1. Surface area terhadap volume berpori

2. Tekanan

3. Temperature

4. Konsentrasi asam

5. Kecepatan aliran

6. Komposisi batuan

Tabel 1. Data Sumur

\begin{tabular}{lr}
\hline \multicolumn{2}{c}{ Data Sumur } \\
\hline Kedalaman Sumur & $7664 \mathrm{ft}$ \\
Kedalaman Formasi & $17.5 \mathrm{ft}$ \\
Temperature sumur & $220 \mathrm{f}$ \\
Tekanan reservoir & $2100 \mathrm{Psi}$ \\
Water cut & $80 \%$ \\
Sg oil & 0.8 \\
Viskositas & $1.2 \mathrm{cp}$ \\
\hline
\end{tabular}

\section{Data Karakteristik Lapisan BRF}

Formasi ini diendapkan secara selaras diatas Formasi Talang Akar. Terdiri dari batugamping terumbu dan batupasir gampingan. Di gunung Gumai tersingkap dari bawah keatas berturutturut napal tufaan, lapisan batugamping koral, batupasir napalan kelabu putih. Ketebalannya antara 200-250 meter dan berumur Miosen Awal. Litologi terdiri dari batugamping, batugamping terumbu, batugamping pasiran, batugamping serpihan, serpih gampingan dan napal kaya foraminifera. Lingkungan pengendapannya adalah laut dangkal.

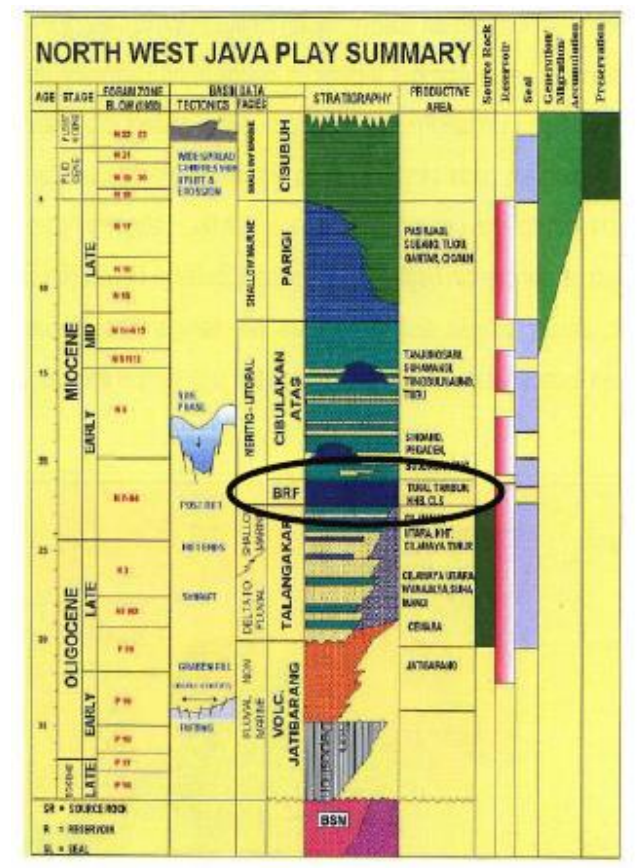

Gambar 1. Data Lapisan Batu Raja Formation 


\section{Karakteristik Batu Gamping (Limestone)}

Batu gamping adalah batuan sedimen yang utamanya tersusun oleh kalsium karbonat (CaCO3) dalam bentuk mineral kalsit. Di Indonesia, batu gamping sering disebut juga dengan istilah batu kapur, sedangkan istilah luarnya biasa disebut "limestone". Batu gamping paling sering terbentuk di perairan laut dangkal. Batu gamping (batu kapur) kebanyakan merupakan batuan sedimen organic yang terbentuk dari akumulasi cangkang, karang, alga, dan pecahanpecahan sisa organisme. Batu ini juga dapat menjadi batuan sedimen kimia yang terbentuk oleh pengendapan kalsium karbonat dari air danau ataupun air laut. Pada prinsipnya, definisi batu gamping mengacu pada batuan yang mengandung setidaknya $50 \%$ berat kalsium karbonat dalam bentuk mineral kalsit. Sisanya, batu gamping dapat mengandung beberapa mineral seperti kuarsa, feldspar, mineral lempung, pirit, siderite dan mineral-mineral lainnya. Bahkan batu gamping juga dapat mengandung nodul besar rijang, nodul pirit ataupun nodul siderite. Kandungan lasium karbonat dari batu gamping memberikan sifat fisik yang sering digunakan untuk mengidentifikasi batuan ini. Biasanya identifikasi batugamping dilakukan dengan meneteskan 5\% asam klorida (HCL).

\section{E. Data Bottom Hole Pressure Test}

Tabel 2. Data BHP Test

\begin{tabular}{|l|l|}
\hline \multicolumn{2}{|c|}{ DATA BHPT } \\
\hline Nama sumur & FIA \\
\hline Depth & $7664 \mathrm{ft}$ \\
\hline Tubing & $27 / 8$ inch \\
\hline Coil tubing & 1 1/2 inch \\
\hline Pref casing & 7 inch \\
\hline 7' packer & $1,817.00 \mathrm{~m}$ \\
\hline Skin & 36.7 \\
\hline Derrick Floor & $6.06 \mathrm{~m}$ \\
\hline Drill Type & Dirrectional Well \\
\hline Well Status & Oil \& Gas Well \\
\hline Position & Onshore \\
\hline Well Type & Development \\
\hline structure & Tambun \\
\hline DATUM & WGS-84 \\
\hline Surface Coordinate & E 724183.17 S 9325708.68 \\
\hline Longitude & E 107 1' 38.573" \\
\hline Latitude & S 6 5' 38.573" \\
\hline Well Remark & Productive \\
\hline
\end{tabular}

Tabel 3. Data Produksi Sumur

\begin{tabular}{llll}
\hline Sumur & Liquid rate & \multicolumn{2}{c}{ Qmax } \\
\hline FIA & $71.8 \mathrm{BOPD}$ & 1.7 & $\mathrm{BFPD}$ \\
\hline
\end{tabular}

\section{F. Prosedur Perhitungan}

Sebelum menghitung proses pengasamannya, perlu dianalisa terlebih dahulu performa dari sumur yang akan diasam, yaitu dengan menganalisa produktivitas formasi dari sumur tersebut. Berikut langkah-langkah yang akan dilakukan.

1. Membuat kurva IPR awal sesuai dengan kandungan reservoir. Pada sumur FIA kandungan 
reservoir yang terkandung adalah satu fasa, artinya di dalam reservoir hanya terkandung satu homogen fluida yaitu hanya minyak saja. Data yang diperlukan adalah :

a. Kandungan reservoir

Kandungan reservoir akan mempengaruhi perubahan laju produksi, karena setiap fluida mempunyai karakter atau kelakuan yang berbeda, misalkan minyak yang pada produksi awal kencang lalu produksi menurun cepat, berbeda dengan air.untuk kandungan reservoir sumur FIA, hanya terkandung 1 fasa yaitu minyak saja.

b. Tekanan reservoir

Tekanan reservoir adalah syarat utama dalam memproduksikan minyak atau gas, minyak atau gas di dalam reservoir akan berusaha keluar karena adanya tekanan reservoir. Tekanan reservoir sumur FIA adalah 2100 Psi.

c. Tekanan dasar sumur

Tekanan dasar sumur (Pwf) adalah tekanan yang digunakan untuk mengontrol tekanan reservoir agar laju produksi menjadi optimal, karena laju produksi terlalu cepat bias mengakibatkan perubahan fasa dari fasa cair menjadi fasa gas. Untuk sumur FIA tekanan dasar sumur adalah 772.19 Psi.

d. Tekanan Gelembung $(\mathrm{Pb})$

Tekanan gelembung besarnya tekanan dimana fasa ciran akan mulai menjadi fasa gas.

Tekanan Gelembung sumur FIA adalah 1.75 Bo, bbl/STB

e. $\quad$ Skin (s)

Skin adalah faktor hambatan yang mempengaruhi laju produksi. Apabila bernilai positif artinya terdapat hambatan. Nilai skin untuk sumur FIA adalah +36.7

Sebelum melakukan pembuatan kurva IPR (inflow Perfomance Relationship) terlebih dahulu harus mengetahui data laju alir (test), dalam menentukan laju alir (test) membutuhkan data analisa core. Data yang dibutuhkan adalah :
a. Ketebalan lapisan
$=17.5 \mathrm{ft}$
b. Viskositas minyak
$=2.2 \mathrm{cp}$
c. Faktor volume formasi minyak
$=1.75 \mathrm{Bo}, \mathrm{bbl} / \mathrm{STB}$
d. Tekanan reservoir pada jari-jari pengurasan $=2100$ Psi
e. Tekanan dasar sumur
$=772.19$ Psi
f. Jari-jari pengurasan
$=820.21 \mathrm{ft}$
g. Jari-jari sumur
$=0.26 \mathrm{ft}$
h. Temperatur reservoir
$=220^{\circ} \mathrm{F}$

Penulis menggunakan rumus :

$$
q=\frac{0.00708 \cdot k \cdot h(p r-p w f)}{\mu \cdot B o\left(\ln \left(\frac{r e}{r w}\right)+S\right.}
$$

Hasil dari perhitungan tersebut didapatlah hasil produksi sebelum dilakukan acidizing yaitu : 71.8 bopd

Berikut adalah hasil IPR sumur FIA sebelum diadakan acidizing: 


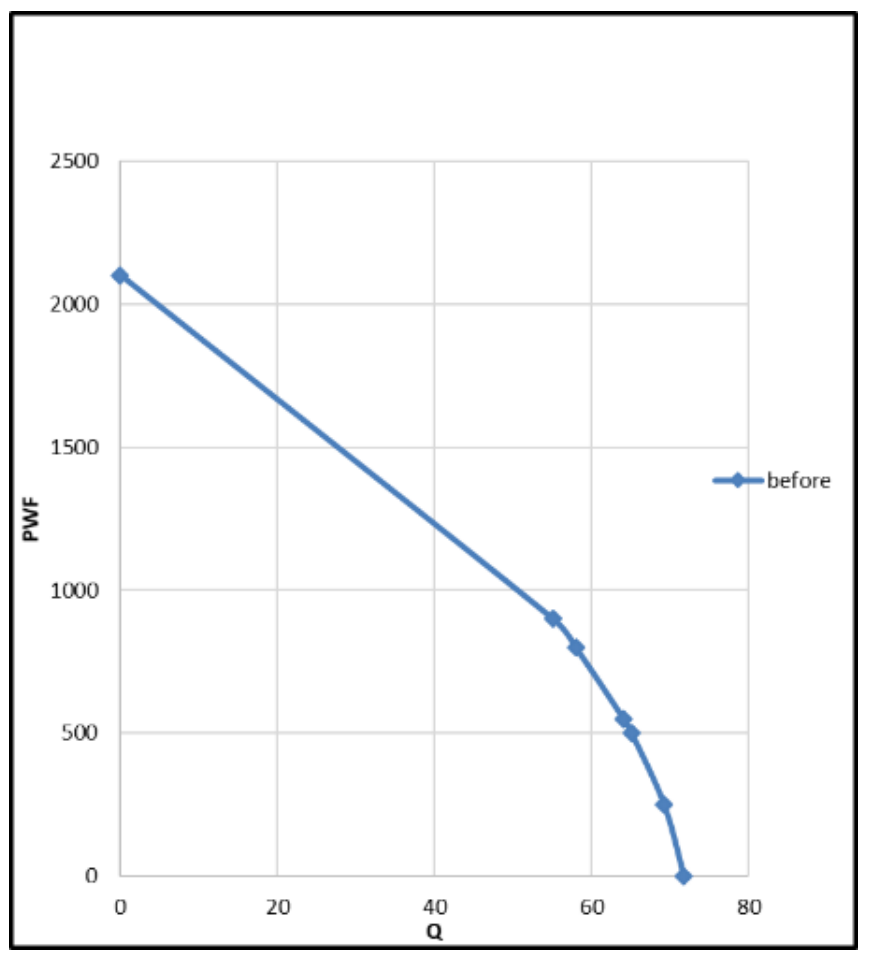

Gambar 2. IPR Sebelum dilakukan Matrix Acidizing

2. Selanjutnya menghitung IPR harapan setelah dilakukan proses pengasaman matrix, penggunaan rumus masih sama seperti perhitungan IPR awal, hanya saja untuk nilai skin setelah stimulasi, kita asumsikan menjadi 0. Hasil perhitungannya adalah 399.2 Bopd.

Berikut adalah hasil IPR harapan setelah dilakukan proses acidizing:

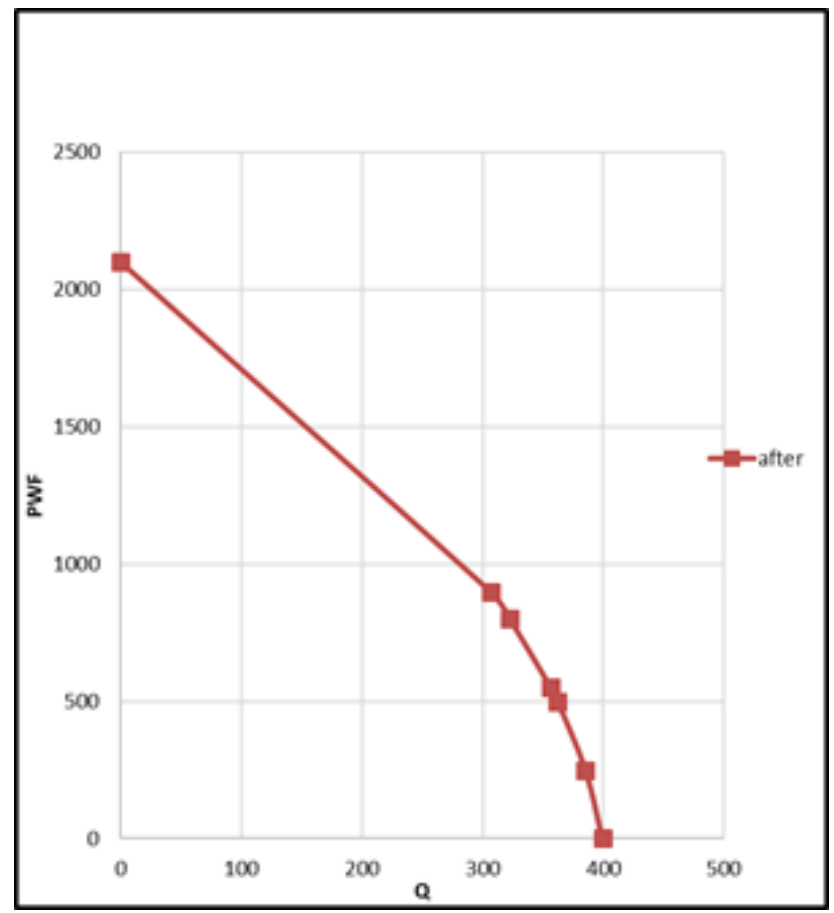

Gambar 3. IPR Setelah dilakukan Matrix Acidizing 


\section{G. Evaluasi Keberhasilan Matrix Acidizing}

Pada sumur FIA tingkat keberhasilan program matrix acidizing dapat dilihat dari laju produksi, dengan membandingkan laju produksi sebelum dan sesudah dilakukan proses pengasam dari sumur tersebut. Jika sumur tersebut mengalami kenaikan laju produksinya, maka program Matrix Acidizing ini dikatan berhasil dan sukses.

Berikut adalah data produksi dan IPR sumur FIA sebelum dan sesudah dilakukan Acidizing :

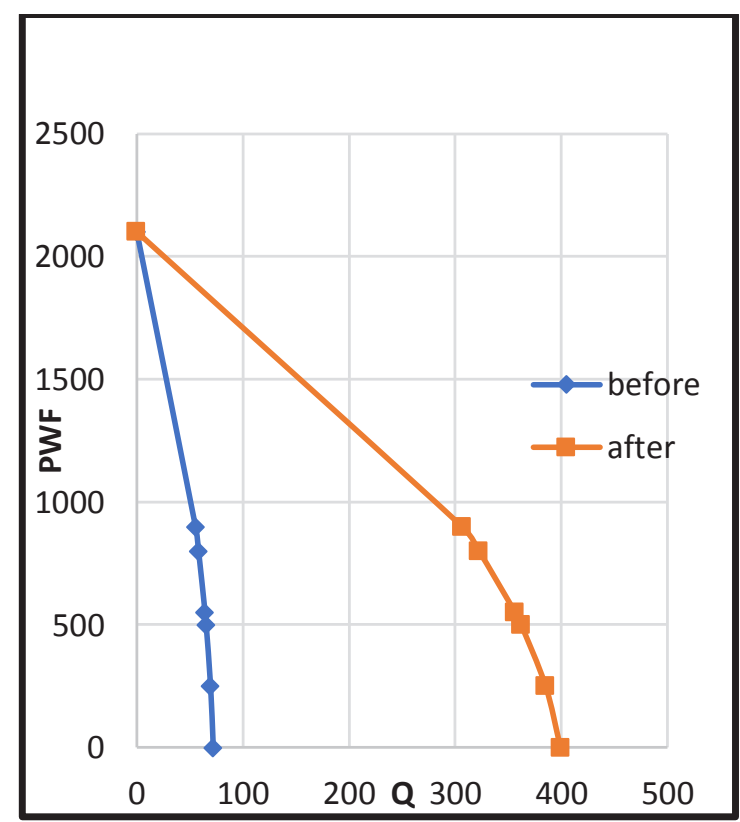

Gambar 4 IPR Before and After Acidizing

Tabel 4. Data produksi sebelum dan sesudah Acidizing

\begin{tabular}{ccc}
\hline Sumur FIA & Liquid rate & \multicolumn{2}{c}{ Qmax } \\
\hline Sebelum & 71.8 BOPD & 359.4 BFPD \\
Sesudah & 399.2 BOPD & $1.4 \quad$ BFPD \\
\hline
\end{tabular}

Berdasarkan Tabel produksi dan Inflow Perfomance Relationship sebelum dan sesudah acidizing dapat disimpulkan bahwa sumur FIA mengalami kenaikan dan sumur FIA dinyatakan sebagai sumur produksi kembali. Program Matrix Acidizing yang dijalankan pada sumur FIA dinyatakan berhasil.

\section{H. Perencanaan Stimulasi Matrix Acidizing dengan Hydrochrolic Acid (HCL)}

\section{Screening Data}

1. screening data yang pertama ialah reservoir data yang meliputi data Temperatur $220^{\circ} \mathrm{F}$, skin 36.7, permeabilitas $47.6 \mathrm{md}$, net thicknes $17.5 \mathrm{ft}$, jari-jari pengurasan $820.21 \mathrm{ft}$, jari-jari sumur $0.26 \mathrm{ft}$.

2. screening data yang kedua ialah fluida Properties yaitu data API oil gravity 38.3 , salinity $32,5 \mathrm{ppm}$, oil viscosity $2.2 \mathrm{cp}$, factor volume formasi minyak 1.75 Bo, bbl/STBO.

3. selanjutnya adalah completion data yang meliputi data berapa interval perfo $7 \mathrm{ft}$, shot per foot(SPF) $5 \mathrm{ft}$. 


\section{Acidizing Program}

Berikut adalah hasil treatment calculation untuk program acidizing yang telah melalui hasil screening data sehingga hasil design aman untuk sumur yang akan di stimulasi

Sebelum masuk pada inti treatment calculation, kita harus terlebih dahulu mengetahui tentang data sumur yang akan kita stimulasi. Untuk sumur FIA data sumur nya adalah :
a. Total depth 2,336 Meter
b. $\quad$ Prev casing 7 inch $23 \mathrm{lb} / \mathrm{ft} 6.366$ Inch.ID 1,547 Meter
c. D.P/Tubing $27 / 8$ inch $6.5 \mathrm{lb} / \mathrm{ft} 2.441$ Inch.ID 1,863 Meter
d. Coil tubing $1 \frac{1 / 2}{2}$ inch $1.212 \mathrm{lb} / \mathrm{ft} 1.212$ Inch.ID 3,200 Meter
e. 7 " packer 1,817 Meter

Setelah diketahui data sumur, data selanjutnya yang wajib untuk diketahui adalah volume calculation. Pentingnya kita mengetahui volume calculation sebelum melakukan stimulasi agar fluid yang di injeksikan sesuai dengan kapasitas yang tersedia.
a. Casing capacity 0.221 cuft, fluid in casing $41 \mathrm{M}$ vol $5.3 \mathrm{Bbl}$
b. Tubing capacity $0.0325 \mathrm{cuft}$, fluid in casing $1,863 \mathrm{M}$ vol $35.38 \mathrm{Bbl}$
c. Coil tubing volume $0.00143 \mathrm{bbl} / \mathrm{ft}$ dikali dengan diameter dalam coil tubing 3,200 Meter $=15 \mathrm{Bbl}$
d. Panjang penetrasi $5.1 \mathrm{ft}$ Radial, Depth perfo 5 Mvol $150 \mathrm{GPF}$

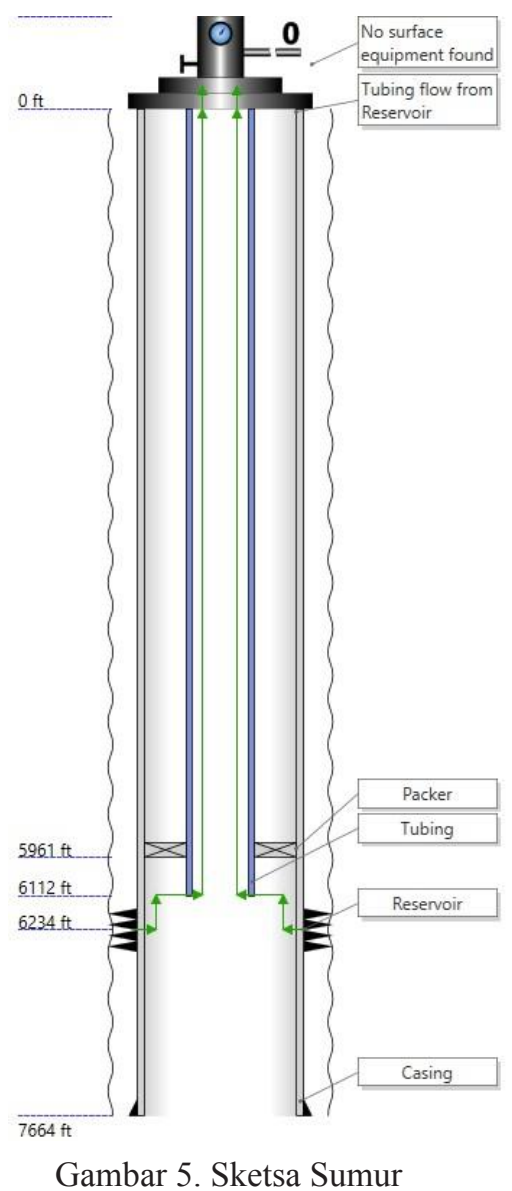


Selanjutnya kita akan menghitung volume awal batuan total, total bersih volume awal batuan, target volume batuan, total target untuk volume karbonat, dan yang terakhir adalah volume karbonat yang akan dipecahkan. Untuk perhitungannya sendiri butuh beberapa parameter yaitu:
a. Berapa penjang penetrasi $=5.1$ Radial
b. Open Hole
$=8.5 \mathrm{ft}$
c. Nilai impurities
$=10 \%$
d. Perforation
$=7 \mathrm{ft}$
e. Porosity
$=15 \%$
f. Porosity Target
$=17$

Berikut adalah rumus untuk mendapatkan nilai :

Initial Bulk Volume

$22 / 7 \times\left((\text { penetration }+ \text { open hole } \div 12 \div 2)^{\wedge} 2 \text {-(open hole } \div 12 \div 2\right)^{\wedge} 2 \times($ perfox 3.281$) \times(1-$ porosity $\div 100$ )

Net Initial Bulk Volume

initial bulk volume $\mathrm{x}(1$-impurities $\div 100)$

Target Bulk Volume

$22 / 7 \times\left((\text { penetration }+ \text { open hole } \div 12 \div 2)^{\wedge} 2 \text {-(open hole } \div 12 \div 2\right)^{\wedge} 2 \times($ perfox 3.281$) \times(1$-porosity target $\div 100$ )

Net Target Carbonat Solved

Target bulk vol x $(1$-impurities $\div 100)$

Volume Carbonat Solved

Net initial bulk volume-net target carbonat solved

setelah melalui perhitungan memakai rumus diatas, hasil yang didapatkan adalah :
a. Initial bulk volume $=1817 \mathrm{cuft}$
b. Net initial bulk volume $=1613 \mathrm{cuft}$
c. Target bulk volume $=1775 \mathrm{cuft}$
d. Net target carbonat solved $=1597 \mathrm{cuft}$
e. Volume carbonat solved $=38.49 \mathrm{cuft}$ 
Tahap selanjutnya ialah menentukan berapa persen konsentrasi asam yang akan di injeksikan. 15\% persen asam bisa menghasilkan 10.7 cuft untuk tiap 1000 gall.

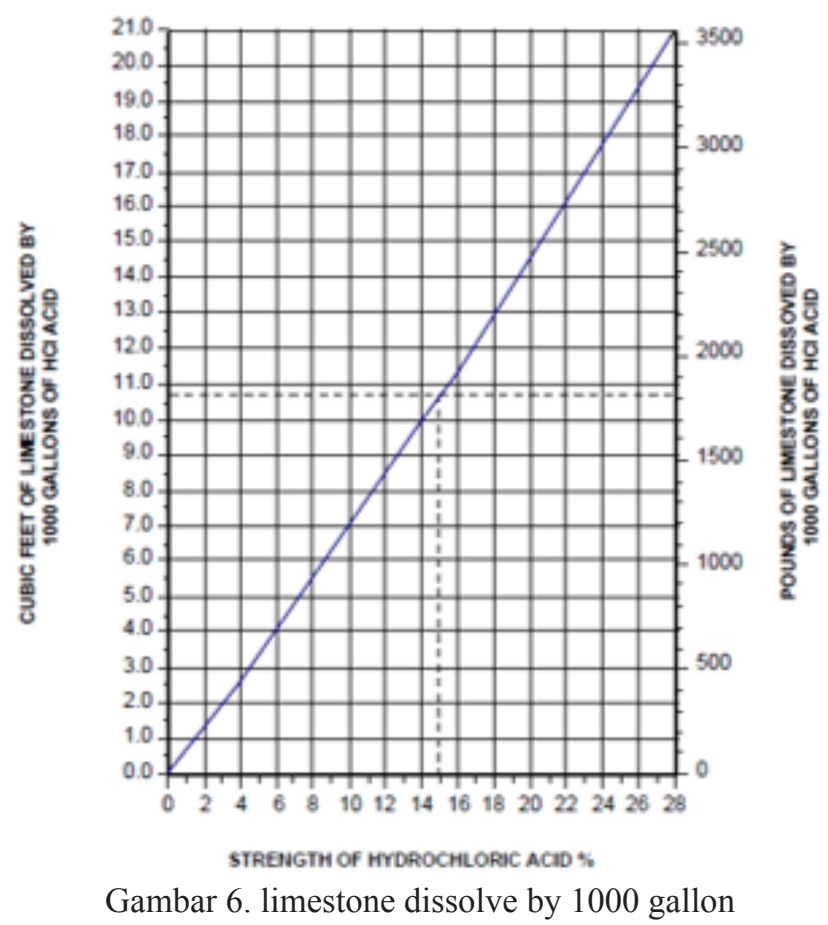

Dari hasil perhitungan treatment calculation dan penentuan berapa persen asam yang akan digunakan, penulis menggunakan rumus pengenceran larutan, rumus yang dipakai ialah :

$$
\mathrm{v} 1 \times \mathrm{m} 1=\mathrm{v} 2 \times \mathrm{m} 2
$$

$\mathrm{v} 1=$ volume awal larutan

$\mathrm{m} 1=$ konsentrasi awal larutan

v2 = volume akhir larutan

$\mathrm{m} 2=$ konsentrasi akhir larutan

Setelah menggunakan rumus pengenceran larutan didapatlah hasil penentuan asam yaitu 34 drum HCL/bbl + 1886 Water dengan menggunakan konsentrasi 15\% HCL. Penulis melampirkan perhitungan pada lampiran 1. Alasan dipilihnya HCL 15\% sebagai main treatment nya adalah karena HCL 15\% mempunyai reaksi yang cukup bagus dengan limestone dan hargnaya yang relatif lebih murah.

Untuk penanggulangannya problem ini sendiri dipilih stimulasi matrix acidizing karena terdapat harga skin positif, harga permeabilitas masih cukup besar sehingga tidak diperlukan proses perekahan hidrolik, dan jenis batuan yang terdapat pada formasi ini adalah karbonat limestone $(\mathrm{CaCo} 3)$.

\section{Fluid design}

Sebelum melaksanakan pengasaman, perlu diketahui tentang penempatan fluida selama stimulasi pengasman. Disini ada 4 tahap pemompaan fluida selama pengasaman yaitu preflush, fluida treatment, fluida overflush dan fluida displacement. 


\section{Pre flush}

Fluida pre-flush harus dipompakan di depan larutan asam untuk menghindari terjadinya kontak langsung antara asam dengan fluida formasi. Hal ini dimaksudkan untuk mengurangi kemungkinan terbentuknya sodium dan potassium fluosilicate sebagai reaksi antara asam dengan ion-ion yang ada. Endapan tersebut terbentuk jika asam fluosilicate dan fluoaluminic bertemu dengan potassium atau sodium yang terkandung dalam air formasi. Jenis fluida yang di gunakan pada perencanaan stimulasi ialah asam HCL. Fluida pre flush menggunakan 420 gall konsentrasi dengan jenis fluida : WATER 915 gpt 384 gall, KCL 167 gpt 70 lbs, BMS-50 25 gpt 11 gall, BSU-5A 5 gpt 2.1 gall, PARAVANS-S 55 gpt 23.1 gall.

\section{Flush atau Fluid Main Treatment}

Pada main treatment ini fluida dirancang untuk mengatasi kerusakan-kerusakan yang ada pada formasi. Fluida treatment yang dipakai dalam pengasaman bergantung pada jenis batuan dan fluida reservoir yang akan di stimulasi. Main acid yang digunakan adalah asam klorida (HCL) yang diyakini memiliki daya larut yang sesuai dengan batuan reservoir yang akan di treatment. Tujuannya adalah untuk mendapatkan saluran linier baru yang konduktif sebagai jalan bagi fluida reservoir untuk mengalir sampai kelubang sumur. Selain itu fluida tersebut diyakini memiliki kecocokan terhadap fluida dan batuan reservoir sehingga tidak akan terjadi reaksi yang menyebabkan terjadinya kerusakan. . Fluida main flush menggunakan 2,456 gall konsentrasi dengan jenis fluida WATER 496 gpt total 1218 gall, HCL 15\% total 1,665 gall, BCL-06 20 gpt total 49 gall, BIC-30 30 gpt total 74 lbs, BCI-02 15 gpt total 37 gall, BSU-12N 10 gpt total 25 gall, BMS-50 25 gpt total 61 gall.

\section{Overflush}

Fluida overflush digunakan untuk mendorong fluida untuk mengatasi kerusakan-kerusakan yang pada formasi. Fluida overflush menggunakan 420 gall konentrasi dengan jenis fluida WATER 990 gpt total 416 gall, BMS 30 gpt total 13 gall, BCL-06 10 GPT total 4 gall.

\section{Displacement}

Fluida displacement bertujuan untuk membersihkan sisa pekerjaan stimulasi di sekitaran lubang bor. Fluida displacement menggunakan 4,200 konsentrasi dengan jenis fluida water 1,000 gpt total 416 gall, KCL 167 ptg total 701,4 lbs

Berhasil atau tidaknya suatu pengasaman sangat tergantung dari pemilihan material dan fluida yang akan digunakan. Perencanaan peralatan mencakup semua alat yang diperlukan dalam pelaksanaan pengasaman. Bahan kimia yang akan digunakan untuk pengasaman disesuaikan dengan jenis kerusakan yang telah diketahui sebelum pengasaman dilaksanakan.

Perencanaan suatu stimulasi pengasaman matrix acidizing tidak hanya menghitung besar jumlah volume asam yang akan diinjeksikan, akan tetapi juga menentukan besar laju tekanan yang akan diinjeksikan kedalam sumur tersebut. Tujuan dari penentuan tekanan ini adalah agar tekanan tidak berlebihan dan merusak dari formasi tersebut, atau dengan kata lain tekanan tidak melebihi tekanan rekah formasi. Suatu metode yang sistematik untuk optimalisasi tekanan dan laju injeksi asam : 
1. Menentukan Gradien Rekah Formasi

$$
G f=\mathrm{a}+(\text { overburden gradien }-\mathrm{a}) \frac{\text { reservoir pressure }}{\text { depth }}
$$

Berdasarkan perhitungan, besar nilai gradien rekah formasi adalah sebesar $0.63 \mathrm{psi} / \mathrm{ft}$. setelah didapatkan hasil gradien rekah formasi, maka didapatkan besar nilai tekanan pecah formasi sebesar 4882 psi.

2. Menghitung Tekanan Laju Injeksi Maksimum Tanpa Menyebabkan Terjadinya Perekahan Pada Batuan

$$
i_{\max }=\frac{4.917 \times 10^{-6} \mathrm{k}_{\mathrm{av}} \mathrm{h}_{\mathrm{n}}\left(\mathrm{G}_{\mathrm{f}} \times \text { depth-Reservoir pressure }\right)}{\mu \ln \left(\frac{r e}{r w}\right)}
$$

Berdasarkan perhitungan, didapatkan besar nilai laju injeksi Maksimum sebesar $5.24 \mathrm{bbl} /$ menit. Untuk menghindari kerusakan atau safety factor dari tekanan Laju Injeksi adalah sebesar 10\% dibawah, oleh karena itu didapatkan besar nilai menjadi $4.71 \mathrm{bbl} / \mathrm{menit}$.

3. Memperkirakan Tekanan Injeksi Permukaan

$$
\text { Pmax }=(\mathrm{Gf}-\text { acid hydrostatic gradient }) \mathrm{x} \text { depth }
$$

Berdasarkan perhitungan pada lampiran 1, besar nilai Tekanan Injeksi Permukaan adalah 1310,5 sebesar psi.

\section{Forecast Sumur FIA PT Pertamina EP Tambun Field}

Forecast bertujuan untuk menentukan besarnya cadangan minyak sisa pada Reservoir sumur FIA dengan metode Decline Curve dengan data-data produksi yang telah didapat dalam kurun waktu tertentu, kemudian akan diketahui kecenderungan penurunan kurva produksi sehingga dapat diperkirakan cadangan minyak sisa dan umur dari reservoir tersebut. Peramalan produksi di masa mendatang sangat penting didalam analisa ekonomi suatu lapangan. Metode Decline Curve adalah salah satu metode yang dapat digunakan untuk menghitung sisa cadangan minyak atau gas dari suatu reservoir yang telah mengalami penurunan produksi dan tidak mengalami perubahan pada metode produksinya, juga dapat dipakai untuk memperkirakan besarnya produksi pada waktu tertentu, serta sebagai bahan analisa untuk pengembangan lapangan. 


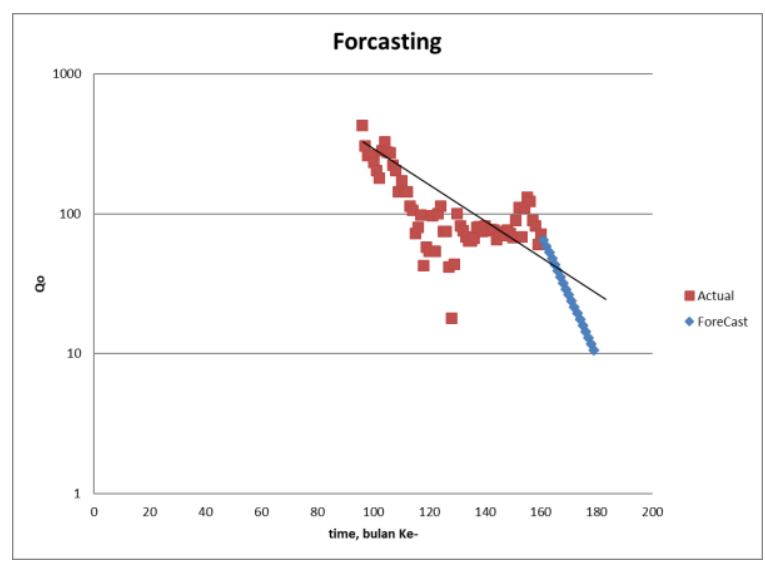

Gambar 7. Forecast Sumur FIA PT Pertamina Asset 3 Cirebon Tambun Field

Menurut perhitungan menggunakan metode Trial Error \& Chi Square Test Normal dapat diketahui bahwa forecast sumur dapat berproduksi hingga tahun 2021 dengan jumlah produksi akhir sebesar 10.6 Bopd. Dengan nilai decline rate sebesar 0.102629 dan menggunakan metode Hyperbolic.

\section{J. Tinjauan Ekonomi}

Merujuk pada peramalan produksi yang telah dilakukan maka dapat kita tinjau keekonomian dari pekerjaan stimulasi pengasaman ini. Parameter yang digunakan dalam tinjauan ekonomi ini antara lain :
a. Indonesia Crude Price
: US\$ 65/BBL
b. Operating Cost
: US\$ 10,491.00\$/BBL
c. Job Cost
: US\$ 100,000.00
d. Government Share
: $70 \%$
e. PEP Share
: $30 \%$
f. $\quad \operatorname{Tax}$
: $30 \%$
g. First Trade Petroleum : $20 \%$
h. Interest
: $10 \%$

Dari hasil analisis keekonomian menggunakan sistem Production Sharing Contract, yang dapat dilihat pada lampiran, didapatkan hasil sebagai berikut:
a. Net Present Value
: US\$1,320,444.60
b. Pay Out Time
: 73 Bulan

\section{KESIMPULAN}

Asam yang digunakan pada program ini adalah asam HCL. Pemilihan asam ini dikarenakan batuan pada reservoir sumur FIA adalah batuan limestone yang mudah larut apabila terkena HCL. Konsentrasi asam yang digunakan adalah HCL 15\%. Sumur FIA membutuhkan 34 drum HCL/bbl + 1886 Water. Berdasarkan hasil IPR before \& After, Program stimulasi dikatan. Menurut Perhitungan Menggunakan metode trial \& error normal dapat diketahui bahwa foreast sumur dapat berproduksi hingga tahun 2021 dengan jumlah produksi akhir sebesar 10.6 BOPD. Dengan niai decline rate sebesar 0.102696 . 


\section{DAFTAR PUSTAKA}

American Petroleum Institute, 2008, API Publication, “API RP 11V6”, Northwest, Washington DC.

Brown, E., Kermit, 1998, “The Technology Of Artificial Lift Method”,Volume 2a, Oklahoma; Pennwell Publishing Company.

Guo, Boyun, 2007, “Petroleum Production Engineer”, Lafayette; Elsevier Science \& Technology Books.

Santosa, Eko, Budhi, 2001, "Metoda Produksi Gas Lift”, Bahan Kuliah, STEM Akamigas, Cepu.

Schlumberger Gas Lift Design and Technology

Takacs, Gabor, 2005, “Gas Lift Manual”, Oklahoma, PennWell Publishing Company, Tulsa. 